\title{
Strategies to Prevent Central Line-Associated Bloodstream Infections in Acute Care Hospitals
}

\section{Citation}

Marschall, Jonas, Leonard A. Mermel, David Classen, Kathleen M. Arias, Kelly Podgorny, Deverick J. Anderson, Helen Burstin, et al. 2008. "Strategies to Prevent Central Line-Associated Bloodstream Infections in Acute Care Hospitals." Infection Control \& Hospital Epidemiology 29 (S1): S22-30. doi:10.1086/591059.

\section{Permanent link}

http://nrs.harvard.edu/urn-3:HUL.InstRepos:41543008

\section{Terms of Use}

This article was downloaded from Harvard University's DASH repository, and is made available under the terms and conditions applicable to Other Posted Material, as set forth at http:// nrs.harvard.edu/urn-3:HUL.InstRepos:dash.current.terms-of-use\#LAA

\section{Share Your Story}

The Harvard community has made this article openly available. Please share how this access benefits you. Submit a story.

Accessibility 


\title{
Strategies to Prevent Central Line-Associated Bloodstream Infections in Acute Care Hospitals
}

\author{
Jonas Marschall, MD; Leonard A. Mermel, DO, ScM; David Classen, MD, MS; Kathleen M. Arias, MS, CIC; \\ Kelly Podgorny, RN, MS, CPHQ; Deverick J. Anderson, MD, MPH; Helen Burstin, MD; David P. Calfee, MD, MS; \\ Susan E. Coffin, MD, MPH; Erik R. Dubberke, MD; Victoria Fraser, MD; Dale N. Gerding, MD; \\ Frances A. Griffin, RRT, MPA; Peter Gross, MD; Keith S. Kaye, MD; Michael Klompas, MD; Evelyn Lo, MD; \\ Lindsay Nicolle, MD; David A. Pegues, MD; Trish M. Perl, MD; Sanjay Saint, MD; Cassandra D. Salgado, MD, MS; \\ Robert A. Weinstein, MD; Robert Wise, MD; Deborah S. Yokoe, MD, MPH
}

\begin{abstract}
PURPOSE
Previously published guidelines are available that provide comprehensive recommendations for detecting and preventing healthcare-associated infections. The intent of this document is to highlight practical recommendations in a concise format designed to assist acute care hospitals in implementing and prioritizing their central line-associated bloodstream infection (CLABSI) prevention efforts. Refer to the Society for Healthcare Epidemiology of America/Infectious Diseases Society of America "Compendium of Strategies to Prevent Healthcare-Associated Infections" Executive Summary and Introduction and accompanying editorial for additional discussion.
\end{abstract}

\section{SECTION 1: RATIONALE AND STATEMENTS OF CONCERN}

1. Patients at risk for CLABSIs in acute care facilities

a. Intensive care unit (ICU) population: The risk of CLABSI in ICU patients is high. Reasons for this include the frequent insertion of multiple catheters, the use of specific types of catheters that are almost exclusively inserted in ICU patients and associated with substantial risk (eg, arterial catheters), and the fact that catheters are frequently placed in emergency circumstances, repeatedly accessed each day, and often needed for extended periods. ${ }^{1,2}$

b. Non-ICU population: Although the primary focus of attention over the past 2 decades has been the ICU setting, recent data suggest that the greatest numbers of patients with central lines are in hospital units outside the ICU, where there is a substantial risk of CLABSI. ${ }^{3-5}$

2. Outcomes associated with hospital-acquired CLABSI a. Increased length of hospital stay ${ }^{6-10}$

b. Increased cost; the non-inflation-adjusted attributable cost of CLABSIs has been found to vary from $\$ 3,700$ to $\$ 29,000$ per episode $\mathrm{e}^{7,10,11}$

3. Independent risk factors for CLABSI (in 2 or more published studies) ${ }^{12-14}$

Note: femoral catheterization was found to be an independent risk factor in 1 study. ${ }^{15}$

a. Factors associated with increased risk

$i$. Prolonged hospitalization before catheterization

ii. Prolonged duration of catheterization

iii. Heavy microbial colonization at the insertion site iv. Heavy microbial colonization of the catheter hub v. Internal jugular catheterization

From the Washington University School of Medicine, St. Louis, Missouri (J.M., E.R.D., V.F.); the Warren Alpert Medical School of Brown University and Rhode Island Hospital, Providence, Rhode Island (L.A.M.); the University of Utah, Salt Lake City (D.C.); the Association for Professionals in Infection Control and Epidemiology (K.M.A.) and the National Quality Forum (H.B.), Washington, D.C.; the Joint Commission, Oakbrook Terrace (K.P., R.W.), the Loyola University Chicago Stritch School of Medicine (D.N.G.) and the Stroger (Cook County) Hospital and Rush University Medical Center (R.A.W.), Chicago, and the Hines Veterans Affairs Medical Center, Hines (D.N.G.), Illinois; the Duke University Medical Center, Durham, North Carolina (D.J.A., K.S.K.); the Mount Sinai School of Medicine, New York, New York (D.P.C.); the Children's Hospital of Philadelphia and University of Pennsylvania School of Medicine, Philadelphia, Pennsylvania (S.E.C.); the Institute for Healthcare Improvement, Cambridge (F.A.G.), and Brigham and Women's Hospital and Harvard Medical School, Boston (D.S.Y., M.K.), Massachusetts; the Hackensack University Medical Center, Hackensack (P.G.), and the University of Medicine and Dentistry-New Jersey Medical School, Newark (P.G.), New Jersey; the David Geffen School of Medicine at the University of California, Los Angeles (D.A.P.); the Johns Hopkins Medical Institutions and University, Baltimore, Maryland (T.M.P.); the Ann Arbor Veterans Affairs Medical Center and the University of Michigan Medical School, Ann Arbor, Michigan (S.S.); the Medical University of South Carolina, Charleston (C.D.S.); and the University of Manitoba, Winnipeg, Canada (E.L., L.N.).

Accepted June 9, 2008; electronically published September 16, 2008.

Infect Control Hosp Epidemiol 2008; 29:S22-S30

(C) 2008 by The Society for Healthcare Epidemiology of America. All rights reserved. 0899-823X/2008/2910S1-0004\$15.00. DOI: 10.1086/591059 
vi. Neutropenia

vii. Prematurity (ie, birth at an early gestational age)

viii. Total parenteral nutrition

$i x$. Substandard care of the catheter (eg, excessive manipulation of the catheter or reduced nurse-to-patient ratio)

b. Factors associated with reduced risk

$i$. Female sex

\section{SECTION 2: STRATEGIES TO DETECT}

\section{L A B S I}

1. Surveillance protocol and definitions

a. Use consistent surveillance methods and definitions to allow comparison with benchmark data

b. Refer to the NHSN Manual: Patient Safety Component Protoco $^{16}$ for information on the appropriate surveillance methodology, including information about blood specimen collection, and for surveillance definitions of CLABSI. The relevant sections of the manual are "Identifying Healthcareassociated Infections (HAI) in NHSN," "Device-Associated Module: Methodology," and "Device-Associated Module: Central Line-Associated Bloodstream Infection (CLABSI) Event.”

\section{SECTION 3: STRATEGIES TO PREVENT}

\section{L A B S I}

1. Existing guidelines and recommendations

a. Several governmental, public health, and professional organizations have published evidence-based guidelines and/or implementation aids regarding the prevention of CLABSI, including the following:

i. The Healthcare Infection Control Practices Advisory Committee ${ }^{17}$

ii. The Institute for Healthcare Improvement ${ }^{18}$ and

iii. Making Health Care Safer, Agency for Healthcare Research and Quality ${ }^{19}$

b. The recommendations in this document focus on central venous catheters (CVCs) unless noted otherwise.

$i$. These recommendations are not stratified on the basis of the type of catheter (eg, tunneled, implanted, cuffed, noncuffed catheter, or dialysis catheter).

ii. These recommendations may not be applicable for prevention of bloodstream infections with other intravascular devices.

\section{Infrastructure requirements}

a. An adequately staffed infection prevention and control program responsible for identifying patients with CLABSI

b. Information technology to collect and calculate catheter-days as a denominator for computing rates of CLABSI and patient-days to allow calculation of CVC utilization; catheter-days from information systems should be validated against a manual method. c. Resources to provide appropriate education and training

d. Adequate laboratory support for timely processing of specimens and reporting of results

\section{Practical implementation}

a. Educate physicians, nurses, and other healthcare personnel about guidelines to prevent CLABSI (eg, with online and paper versions). These guidelines should be easily accessible.

b. Develop and implement a catheter insertion checklist. Educate nurses, physicians, and other healthcare personnel involved in catheter insertion, regarding the use of the catheter insertion checklist.

c. Educate healthcare personnel about the insertion and maintenance of catheters. ${ }^{20}$ One method is to require healthcare personnel to complete an educational program including a posteducation test to ensure their knowledge and competency before being allowed to insert CVCs.

d. Establish catheter insertion kits/carts containing all necessary items for insertion.

\section{SECTION 4：RECOMMENDATIONS FOR}

\section{IMPLEMENTING PREVENTION AND}

\section{MONITORING STRATEGIES}

Recommendations for preventing and monitoring CLABSI are summarized in the following section. They are designed to assist acute care hospitals in prioritizing and implementing their CLABSI prevention efforts. Criteria for grading the strength of the recommendation and quality of evidence are described in the Table.

Note: Some of the following measures have been combined into a "prevention bundle" that focuses on catheter insertion (eg, measures B.2, B.3, B.5, B.6, and C.2). ${ }^{22-24}$

\section{Basic practices for prevention and monitoring of CLABSI: recommended for all acute care hospitals}

A. Before insertion

1. Educate healthcare personnel involved in the insertion, care, and maintenance of CVCs about CLABSI prevention (A-II). ${ }^{20,25-28}$

a. Include the indications for catheter use, appropriate insertion and maintenance, the risk of CLABSI, and general infection prevention strategies.

b. Ensure that all healthcare personnel involved in catheter insertion and maintenance complete an educational program regarding basic practices to prevent CLABSI before performing these duties.

c. Periodically assess healthcare personnel knowledge of and adherence to preventive measures.

d. Ensure that any healthcare professional who inserts a CVC undergoes a credentialing process (as established 


\begin{tabular}{ll} 
TABLE. Strength of Recommendation and Quality of Evidence \\
\hline Category/grade & \multicolumn{1}{c}{ Definition } \\
\hline $\begin{array}{l}\text { Strength of recommendation } \\
\text { A }\end{array}$ & Good evidence to support a recommendation for use \\
B & Moderate evidence to support a recommendation for use \\
C & Poor evidence to support a recommendation \\
Quality of evidence & Evidence from $\geqslant 1$ properly randomized, controlled trial \\
I & Evidence from $\geqslant 1$ well-designed clinical trial, without \\
II & randomization; from cohort or case-control analytic \\
& studies (preferably from $>1$ center); from multiple \\
& time series; or from dramatic results of uncontrolled \\
& experiments \\
Evidence from opinions of respected authorities, based \\
on clinical experience, descriptive studies, or reports \\
from expert committees
\end{tabular}

Note. Adapted from the Canadian Task Force on the Periodic Health Examination. ${ }^{21}$

by the individual healthcare institution) to ensure their competency before they independently insert a CVC.

\section{B. At insertion}

1. Use a catheter checklist to ensure adherence to infection prevention practices at the time of CVC insertion (B-II). ${ }^{23,29}$

a. Use a checklist to ensure and document compliance with aseptic technique.

i. CVC insertion should be observed by a nurse, physician, or other healthcare personnel who has received appropriate education (see above), to ensure that aseptic technique is maintained.

b. These healthcare personnel should be empowered to stop the procedure if breaches in aseptic technique are observed.

2. Perform hand hygiene before catheter insertion or manipulation (B-II)..$^{30-33}$

a. Use an alcohol-based waterless product or antiseptic soap and water.

$i$. Use of gloves does not obviate hand hygiene.

3. Avoid using the femoral vein for central venous access in adult patients (A-I). ${ }^{15,34,35}$

a. Use of the femoral access site is associated with greater risk of infection and deep venous thrombosis in adults.

$i$. Increased risk of infection with femoral catheters may be limited to overweight adult patients with a body mass index higher than 28.4. ${ }^{36}$

ii. Femoral vein catheterization can be done without general anesthesia in children and has not been associated with an increased risk of infection in children. ${ }^{37}$ b. Several nonrandomized studies show that the subclavian vein site is associated with a lower risk of CLABSI than is the internal jugular vein, but the risks and benefits in light of potential infectious and noninfectious complications must be considered on an individual basis when determining which insertion site to use.

c. The use of peripherally inserted CVCs is not an evidence-based strategy to reduce the risk of CLABSI.

$i$. The risk of infection with peripherally inserted CVCs in ICU patients approaches that with CVCs placed in the subclavian or internal jugular veins. ${ }^{38}$

4. Use an all-inclusive catheter cart or kit (B-II). ${ }^{23}$

a. A catheter cart or kit that contains all necessary components for aseptic catheter insertion is to be available and easily accessible in all units where CVCs are inserted.

5. Use maximal sterile barrier precautions during CVC insertion (A-I). ${ }^{39-42}$

a. Use maximal sterile barrier precautions.

i. A mask, cap, sterile gown, and sterile gloves are to be worn by all healthcare personnel involved in the catheter insertion procedure.

ii. The patient is to be covered with a large sterile drape during catheter insertion.

b. These measures must also be followed when exchanging a catheter over a guidewire.

6. Use a chlorhexidine-based antiseptic for skin preparation in patients older than 2 months of age (A-I). ${ }^{43-46}$

a. Before catheter insertion, apply an alcoholic chlorhexidine solution containing a concentration of chlorhexidine gluconate greater than $0.5 \%$ to the insertion site.

$i$. The antiseptic solution must be allowed to dry before making the skin puncture.

ii. Chlorhexidine products are not approved by the US Food and Drug Administration for children younger 
than 2 months of age; povidone-iodine can be used for children in this age group.

\section{After insertion}

1. Disinfect catheter hubs, needleless connectors, and injection ports before accessing the catheter (B-II). ${ }^{47-49}$

a. Before accessing catheter hubs or injection ports, clean them with an alcoholic chlorhexidine preparation or $70 \%$ alcohol to reduce contamination.

2. Remove nonessential catheters (A-II). ${ }^{50,51}$

a. Assess the need for continued intravascular access on a daily basis during multidisciplinary rounds. Remove catheters not required for patient care.

3. For nontunneled CVCs in adults and adolescents, change transparent dressings and perform site care with a chlorhexidine-based antiseptic every 5-7 days or more frequently if the dressing is soiled, loose, or damp; change gauze dressings every 2 days or more frequently if the dressing is soiled, loose, or damp (A-I). ${ }^{52,53}$

4. Replace administration sets not used for blood, blood products, or lipids at intervals not longer than 96 hours (AII). ${ }^{54}$

\section{Perform surveillance for CLABSI (B-II).$^{55}$}

a. Measure unit-specific incidence of CLABSI (CLABSIs per 1,000 catheter-days) and report the data on a regular basis to the units, physician and nursing leadership, and hospital administrators overseeing the units.

b. Compare CLABSI incidence with historical data for individual units and with national rates (ie, data from the National Healthcare Safety Network ${ }^{56}$ ).

c. CLABSI has been documented in large numbers of non-ICU patients with CVCs. Surveillance for CLABSI in these settings requires additional resources. ${ }^{4,5,57}$

6. Use antimicrobial ointments for hemodialysis catheter insertion sites (A-I) ${ }^{58-62}$

a. Povidone-iodine or polysporin ointment should be applied to hemodialysis catheter insertion sites in patients with a history of recurrent Staphylococcus aureus CLABSI.

b. Mupirocin ointment should not be applied to the catheter insertion site due to the risks of mupirocin resistance and damage to polyurethane catheters.

\section{Accountability}

1. The hospital's chief executive officer and senior management are responsible for ensuring that the healthcare system supports an infection prevention and control program that effectively prevents the occurrence of CLABSI.
2. Senior management is accountable for ensuring that an adequate number of trained personnel are assigned to the infection prevention and control program.

3. Senior management is accountable for ensuring that healthcare personnel, including licensed and nonlicensed personnel, are competent to perform their job responsibilities.

4. Direct healthcare providers (such as physicians, nurses, aides, and therapists) and ancillary personnel (such as housekeeping and equipment-processing personnel) are responsible for ensuring that appropriate infection prevention and control practices are used at all times (including hand hygiene, standard and isolation precautions, cleaning and disinfection of equipment and the environment, aseptic technique when inserting and caring for CVCs, maximal barrier precautions, appropriate site selection, and daily assessment of the need for a $\mathrm{CVC})$.

5. Hospital and unit leaders are responsible for holding personnel accountable for their actions.

6. The person who manages the infection prevention and control program is responsible for ensuring that an active program to identify CLABSIs is implemented, that data on CLABSIs are analyzed and regularly provided to those who can use the information to improve the quality of care (eg, unit staff, clinicians, and hospital administrators), and that evidence-based practices are incorporated into the program.

7. Individuals responsible for healthcare personnel and patient education are accountable for ensuring that appropriate training and educational programs to prevent CLABSIs are developed and provided to personnel, patients, and families.

8. Personnel from the infection prevention and control program, laboratory, and information technology departments are responsible for ensuring that systems are in place to support the surveillance program.

\section{Special approaches for the prevention of CLABSI}

Perform a CLABSI risk assessment. These special approaches are recommended for use in locations and/or populations within the hospital that have unacceptably high CLABSI rates despite implementation of the basic CLABSI prevention strategies listed above.

1. Bathe ICU patients older than 2 months of age with a chlorhexidine preparation on a daily basis (B-II).$^{63}$

a. Chlorhexidine products are not approved by the US Food and Drug Administration for children younger than 2 months of age but are used at some institutions for cleaning CVC insertion sites or as a sponge dressing for children in this age group. 
b. A povidone-iodine preparation should be used to clean CVC insertion sites for children younger than 2 months of age, especially low-birth-weight neonates.

2. Use antiseptic- or antimicrobial-impregnated CVCs for adult patients (A-I) ${ }^{64-70}$

a. The risk of CLABSI is reduced with some currently marketed catheters impregnated with antiseptics (eg, chlorhexidine-silver sulfadiazine) or antimicrobials (eg, minocycline-rifampin). Consider the use of such catheters in the following circumstances:

$i$. Hospital units or patient populations have a CLABSI rate higher than the institutional goal, despite compliance with basic CLABSI prevention practices.

ii. Patients have limited venous access and a history of recurrent CLABSI.

iii. Patients are at heightened risk for severe sequelae from a CLABSI (eg, patients with recently implanted intravascular devices, such as a prosthetic heart valve or aortic graft).

b. These catheters are not approved by the US Food and Drug Administration for use in children.

$i$. Preliminary data suggest that antimicrobial-impregnated catheters appear to be safe and may hold promise for pediatric ICU patients. ${ }^{71,72}$

3. Use chlorhexidine-containing sponge dressings for CVCs in patients older than 2 months of age (B-I). ${ }^{73-75}$

a. Consider the addition of such a dressing in the following circumstances:

i. Hospital units or patient populations have a CLABSI rate higher than the institutional goal, despite compliance with an evidence-based prevention bundle.

ii. Patients have limited venous access and a history of recurrent CLABSI.

iii. Patients are at heightened risk for severe sequelae from a CLABSI (eg, patients with recently implanted intravascular devices, such as a prosthetic heart valve or aortic graft).

b. Do not use chlorhexidine-containing sponge dressings for low-birth-weight neonates.

4. Use antimicrobial locks for CVCs (A-I). ${ }^{76-80}$

a. Antibiotic locks are created by filling the lumen of the catheter with a supraphysiologic concentration of an antimicrobial solution and leaving the solution in place until the catheter hub is reaccessed. Such an approach can reduce the risk of CLABSI. Because of concerns regarding the potential for the emergence of resistance in exposed organisms and the potential for systemic toxicity from leakage of the lock solution into the bloodstream, use antimicrobial locks as a preventative strategy only for the following: $i$. Prophylaxis for patients with limited venous access and a history of recurrent CLABSI.

ii. Patients who are at heightened risk for severe sequelae from a CLABSI (eg, patients with recently implanted intravascular devices such as a prosthetic heart valve or aortic graft).

\section{Approaches that should not be considered a routine part of CLABSI prevention}

1. Do not use antimicrobial prophylaxis for short-term or tunneled catheter insertion or while catheters are in situ (AI). ${ }^{81-84}$

a. Systemic antimicrobial prophylaxis is not recommended.

2. Do not routinely replace CVCs or arterial catheters (AI). ${ }^{85-87}$

a. Routine catheter replacement is not recommended.

3. Do not routinely use positive-pressure needleless connectors with mechanical valves before a thorough assessment of risks, benefits, and education regarding proper use (BII). ${ }^{88-91}$

a. Routine use of the currently marketed devices that are associated with an increased risk of CLABSI is not recommended.

\section{Unresolved issues}

1. Nurse-to-patient ratio and use of float nurses in ICUs ${ }^{92-94}$

a. Observational studies suggest that there should be a nurse-to-patient ratio of at least $2: 1$ in ICUs where nurses are managing patients with CVCs and that the number of float nurses working in the ICU environment should be minimized. Formal recommendations await the results of interventional trials.

2. Intravenous therapy teams for reducing CLABSI rates ${ }^{95}$

a. Studies have shown that an intravenous therapy team responsible for insertion and maintenance of peripheral intravenous catheters reduces the risk of bloodstream infections. ${ }^{96}$ However, few studies have been performed regarding the impact of intravenous therapy teams on CLABSI rates.

3. Surveillance of other types of catheters (eg, peripheral arterial catheters $)^{1,2}$

a. Peripheral arterial catheters have not been included in most surveillance systems, although they are associated with a risk of bloodstream infection. Future surveillance systems may need to include bloodstream infections associated with these types of catheters. 
4. Estimating catheter-days for determining incidence density of CLABSI

a. Surveillance can be facilitated in settings with a limited workforce by estimating the number of catheterdays. $^{97,98}$

\section{SECTION 5：PERFORMANCE MEASURES}

\section{Internal reporting}

These performance measures are intended to support internal hospital quality improvement efforts and do not necessarily address external reporting needs.

The process and outcome measures suggested here are derived from published guidelines, other relevant literature, and the opinion of the authors. Report process and outcome measures to senior hospital leadership, nursing leadership, and clinicians who care for patients at risk for CLABSI.

A. Process measures (in rank order from highest to lowest priority)

1. Compliance with CVC insertion guidelines as documented on an insertion checklist

a. Assess compliance with the checklist in all hospital settings where CVCs are inserted (eg, ICUs, emergency department, operating room, radiology, and general wards) and assign healthcare personnel familiar with catheter care to this task.

$i$. For an example of a central catheter checklist, see the Institute for Healthcare Improvement Web site. ${ }^{99}$

b. Measure the percentage of CVC insertion procedures in which compliance with appropriate hand hygiene, use of maximal sterile barrier precautions, and use of chlorhexidine-based cutaneous antisepsis of the insertion site is documented.

i. Numerator: number of CVC insertions that have documented the use of all 3 interventions (hand hygiene, maximal barrier precautions, and chlorhexidine-based cutaneous antiseptic use) performed at the time of CVC insertion.

ii. Denominator: number of all CVC insertions.

iii. Multiply by 100 so that the measure is expressed as a percentage.

2. Compliance with documentation of daily assessment regarding the need for continuing CVC access

a. Measure the percentage of patients with a CVC for whom there is documentation of daily assessment.

$i$. Numerator: number of patients with a CVC for whom there is documentation of daily assessment.

ii. Denominator: number of patients with a CVC.

iii. Multiply by 100 so that the measure is expressed as a percentage.
3. Compliance with cleaning of catheter hubs and injection ports before they are accessed

a. Assess compliance through observations of practice.

$i$. Numerator: number of times that a catheter hub or port is observed to be cleaned before being accessed.

ii. Denominator: number of times a catheter hub or port is observed to be accessed.

iii. Multiply by 100 so that the measure is expressed as a percentage.

4. Compliance with avoiding the femoral vein site for CVC insertion in adult patients

a. Perform point prevalence surveys or use information collected as part of the central line insertion checklist to determine the percentage of patients whose CVCs are in the femoral vein versus the subclavian or internal jugular veins.

b. Calculate the percentage of patients with a femoral vein catheter.

i. Numerator: number of patients with a CVC in the femoral vein.

ii. Denominator: total number of patients with a CVC in unit population being assessed.

iii. Multiply by 100 so that the measure is expressed as a percentage.

\section{B. Outcome measures}

1. CLABSI rate

a. Use National Healthcare Safety Network definitions. $i$. Numerator: number of CLABSIs in each unit assessed (using National Healthcare Safety Network definitions).

ii. Denominator: total number of catheter-days in each unit assessed (using National Healthcare Safety Network definitions).

iii. Multiply by 1,000 so that the measure is expressed as number of CLABSIs per 1,000 catheter-days.

iv. Risk adjustment: stratify CLABSI rates by type of patient-care unit. ${ }^{100-102}$

(a) Report comparisons based on historical data and National Healthcare Safety Network data, if available. $^{56}$

\section{External reporting}

There are many challenges in providing useful information to consumers and other stakeholders while preventing unintended adverse consequences of public reporting of healthcare-associated infections. ${ }^{103}$ Recommendations for public reporting of healthcare-associated infections have been provided by the Healthcare Infection Control Practices Advisory Committee, ${ }^{104}$ the Healthcare-Associated Infection Working Group of the Joint Public Policy Committee, ${ }^{105}$ and the National Quality Forum. ${ }^{106}$ 


\section{A. State and federal requirements}

1. Hospitals in states that have mandatory reporting requirements for CLABSI must collect and report the data required by the state.

2. For information on state and federal requirements, contact your state or local health department.

\section{B. External quality initiatives}

1. Hospitals that participate in external quality initiatives or state programs must collect and report the data required by the initiative or the program.

\section{ACKNOWLEDGMENTS}

For Potential Conflicts of Interest statements and information on financial support, please see the Acknowledgments in the Executive Summary, on page S20 of this supplement.

Address reprint requests to the Reprints Coordinator, University of Chicago Press, 1427 E. 60th St., Chicago, IL 60637 (reprints@press.uchicago.edu) or contact the journal office (iche@press.uchicago.edu).

\section{REFERENCES}

1. Maki DG, Kluger DM, Crnich CJ. The risk of bloodstream infection in adults with different intravascular devices: a systematic review of 200 published prospective studies. Mayo Clin Proc 2006; 81:1159-1171.

2. Esteve F, Pujol M, Limon E, et al. Bloodstream infection related to catheter connections: a prospective trial of two connection systems. $J$ Hosp Infect 2007; 67:30-34.

3. Climo M, Diekema D, Warren DK, et al. Prevalence of the use of central venous access devices within and outside of the intensive care unit: results of a survey among hospitals in the prevention epicenter program of the Centers for Disease Control and Prevention. Infect Control Hosp Epidemiol 2003; 24:942-945.

4. Vonberg RP, Behnke M, Geffers C, et al. Device-associated infection rates for non-intensive care unit patients. Infect Control Hosp Epidemiol 2006; 27:357-361.

5. Marschall J, Leone C, Jones M, Nihill D, Fraser VJ, Warren DK. Catheter-associated bloodstream infections in general medical patients outside the intensive care unit: a surveillance study. Infect Control Hosp Epidemiol 2007; 28:905-909.

6. Pittet D, Tarara D, Wenzel RP. Nosocomial bloodstream infection in critically ill patients: excess length of stay, extra costs, and attributable mortality. JAMA 1994; 271:1598-1601.

7. DiGiovine B, Chenoweth C, Watts C, Higgins M. The attributable mortality and costs of primary nosocomial bloodstream infections in the intensive care unit. Am J Respir Crit Care Med 1999; 160:976-981.

8. Renaud B, Brun-Buisson C, ICU-Bacteremia Study Group. Outcomes of primary and catheter-related bacteremia: a cohort and case-control study in critically ill patients. Am J Respir Crit Care Med 2001; 163: 1584-1590.

9. Dimick JB, Pelz RK, Consunji R, Swoboda SM, Hendrix CW, Lipsett PA. Increased resource use associated with catheter-related bloodstream infection in the surgical intensive care unit. Arch Surg 2001; 136:229234.

10. Warren DK, Quadir WW, Hollenbeak CS, et al. Attributable cost of catheter-associated bloodstream infection among intensive care patients in a nonteaching hospital. Crit Care Med 2006; 34:2084-2089.

11. Mermel LA. Prevention of intravascular catheter-related infections (published correction appears in Ann Intern Med 2000; 133:5). Ann Intern Med 2000; 132:391-402.

12. Mermel LA. Infections caused by intravascular devices. In: Pffeifer JA, ed. APIC Text of Infection Control and Epidemiology. 2nd ed. St. Louis: Mosby; 2000:30-38.

13. Almuneef MA, Memish ZA, Balkhy HH, Hijazi O, Cunningham G, Francis C. Rate, risk factors and outcomes of catheter-related bloodstream infection in a paediatric intensive care unit in Saudi Arabia. $J$ Hosp Infect 2006; 62:207-213.

14. Alonso-Echanove J, Edwards JR, Richards MJ, et al. Effect of nurse staffing and antimicrobial-impregnated central venous catheters on the risk for bloodstream infections in intensive care units. Infect Control Hosp Epidemiol 2003; 24:916-925.

15. Lorente L, Henry C, Martin MM, Jimenez A, Mora ML. Central venous catheter-related infection in a prospective and observational study of 2,595 catheters. Crit Care 2005; 9:R631-R635.

16. National Healthcare Safety Network, Centers for Disease Control and Prevention. The National Healthcare Safety Network (NHSN) manual: patient safety component protocol. January 2008. Available at: http://www.cdc.gov/ncidod/dhqp/pdf/nhsn/NHSN_Manual _PatientSafetyProtocol_CURRENT.pdf. Accessed July 30, 2008.

17. O'Grady NP, Alexander M, Dellinger EP, et al. Guidelines for the prevention of intravascular catheter-related infections. MMWR Recomm Rep 2002; 51(RR-10):1-29.

18. Institute for Healthcare Improvement. Available at: http://www.ihi.org/ ihi. Accessed July 15, 2008

19. Saint S. Prevention of intravascular catheter-associated infections. In Making Health Care Safer: A Critical Analysis of Patient Safety Practices. Evidence report/technology assessment, no. 43. AHRQ publication no. 01-E058. Rockville, MD: Agency for Healthcare Research and Quality; 2001:163-183. Available at: http://www.ahrq.gov/clinic/ptsafety/. Accessed July 16, 2008.

20. Sherertz RJ, Ely EW, Westbrook DM, et al. Education of physicians-intraining can decrease the risk for vascular catheter infection. Ann Intern Med 2000; 132:641-648.

21. Canadian Task Force on the Periodic Health Examination. The periodic health examination. Can Med Assoc J 1979; 121:1193-1254.

22. Pronovost P, Needham D, Berenholtz S, et al. An intervention to decrease catheter-related bloodstream infections in the ICU. N Engl J Med 2006; 355:2725-2732.

23. Berenholtz SM, Pronovost PJ, Lipsett PA, et al. Eliminating catheterrelated bloodstream infections in the intensive care unit. Crit Care Med 2004; 32:2014-2020

24. Muto C, Herbert C, Harrison E, et al. Reduction in central line-associated bloodstream infections among patients in intensive care unitsPennsylvania, April 2001-March 2005. MMWR Morb Mortal Wkly Rep 2005; 54:1013-1016.

25. Eggimann P, Harbarth S, Constantin MN, Touveneau S, Chevrolet JC, Pittet D. Impact of a prevention strategy targeted at vascular-access care on incidence of infections acquired in intensive care. Lancet 2000; 355: 1864-1868.

26. Coopersmith CM, Rebmann TL, Zack JE, et al. Effect of an education program on decreasing catheter-related bloodstream infections in the surgical intensive care unit. Crit Care Med 2002; 30:59-64.

27. Warren DK, Zack JE, Cox MJ, Cohen MM, Fraser VJ. An educational intervention to prevent catheter-associated bloodstream infections in a nonteaching, community medical center. Crit Care Med 2003; 31:19591963.

28. Warren DK, Zack JE, Mayfield JL, et al. The effect of an education program on the incidence of central venous catheter-associated bloodstream infection in a medical ICU. Chest 2004; 126:1612-1618.

29. Tsuchida T, Makimoto K, Toki M, Sakai K, Onaka E, Otani Y. The effectiveness of a nurse-initiated intervention to reduce catheter-associated bloodstream infections in an urban acute hospital: an intervention study with before and after comparison. Int J Nurs Stud 2007; 44: 1324-1333.

30. Occupational Health \& Safety Administration, US Department of Labor. Available at: http://www.osha.gov/. Accessed July 15, 2008. 
31. Yilmaz G, Koksal I, Aydin K, Caylan R, Sucu N, Aksoy F. Risk factors of catheter-related bloodstream infections in parenteral nutrition catheterization. JPEN J Parenter Enteral Nutr 2007; 31:284-287.

32. Boyce JM, Pittet D. Guideline for hand hygiene in health-care settings: recommendations of the Healthcare Infection Control Practices Advisory Committee and the HICPAC/SHEA/APIC/IDSA Hand Hygiene Task Force. Society for Healthcare Epidemiology of America/Association for Professionals in Infection Control/Infectious Diseases Society of America. MMWR Recomm Rep 2002; 51(RR-16):1-45.

33. Rosenthal VD, Guzman S, Safdar N. Reduction in nosocomial infection with improved hand hygiene in intensive care units of a tertiary care hospital in Argentina. Am J Infect Control 2005; 33:392-397.

34. Goetz AM, Wagener MM, Miller JM, Muder RR. Risk of infection due to central venous catheters: effect of site of placement and catheter type. Infect Control Hosp Epidemiol 1998; 19:842-845.

35. Merrer J, De Jonghe B, Golliot F, et al. Complications of femoral and subclavian venous catheterization in critically ill patients: a randomized controlled trial. JAMA 2001; 286:700-707.

36. Parienti JJ, Thirion M, Mégarbane B, et al. Femoral versus jugular central catheterization in patients requiring renal replacement therapy: a randomized controlled study. JAMA 2008; 299:2413-2422.

37. De Jonge RCJ, Polderman KH, Gemke RJBJ. Central venous catheter use in the pediatric patient: mechanical and infectious complications. Pediatr Crit Care Med 2005; 6:329-339.

38. Safdar N, Maki DG. Risk of catheter-related bloodstream infection with peripherally inserted central venous catheters used in hospitalized patients. Chest 2005; 128:489-495.

39. Mermel LA, McCormick RD, Springman SR, Maki DG. The pathogenesis and epidemiology of catheter-related infection with pulmonary artery Swan-Ganz catheters: a prospective study utilizing molecular subtyping. Am J Med 1991; 91:197S-205S.

40. Raad II, Hohn DC, Gilbreath BJ, et al. Prevention of central venous catheter-related infections by using maximal sterile barrier precautions during insertion. Infect Control Hosp Epidemiol 1994; 15:231-238.

41. Hu KK, Lipsky BA, Veenstra DL, Saint S. Using maximal sterile barriers to prevent central venous catheter-related infection: a systematic evidence-based review. Am J Infect Control 2004; 32:142-146.

42. Young EM, Commiskey ML, Wilson SJ. Translating evidence into practice to prevent central venous catheter-associated bloodstream infections: a systems-based intervention. Am J Infect Control 2006; 34:503506.

43. Maki DG, Ringer M, Alvarado CJ. Prospective randomised trial of povidone-iodine, alcohol, and chlorhexidine for prevention of infection associated with central venous and arterial catheters. Lancet 1991; 338: 339-343.

44. Garland JS, Buck RK, Maloney P, et al. Comparison of $10 \%$ povidoneiodine and $0.5 \%$ chlorhexidine gluconate for the prevention of peripheral intravenous catheter colonization in neonates: a prospective trial. Pediatr Infect Dis J 1995; 14:510-516.

45. Humar A, Ostromecki A, Direnfeld J, et al. Prospective randomized trial of $10 \%$ povidone-iodine versus $0.5 \%$ tincture of chlorhexidine as cutaneous antisepsis for prevention of central venous catheter infection. Clin Infect Dis 2000; 31:1001-1007.

46. Chaiyakunapruk N, Veenstra DL, Lipsky BA, Saint S. Chlorhexidine compared with povidone-iodine solution for vascular catheter-site care: a meta-analysis. Ann Intern Med 2002; 136:792-801.

47. Salzman MB, Isenberg HD, Rubin LG. Use of disinfectants to reduce microbial contamination of hubs of vascular catheters. J Clin Microbiol 1993; 31:475-479.

48. Luebke MA, Arduino MJ, Duda DL, et al. Comparison of the microbial barrier properties of a needleless and a conventional needle-based intravenous access system. Am J Infect Control 1998; 26:437-441.

49. Casey AL, Worthington T, Lambert PA, Quinn D, Faroqui, Elliott TS. A randomized, prospective clinical trial to assess the potential infection risk associated with the PosiFlow ${ }^{\circledR}$ needleless connector. J Hosp Infect 2003; 54:288-293.

50. Lederle FA, Parenti CM, Berskow LC, Ellingson KJ. The idle intravenous catheter. Ann Intern Med 1992; 116:737-738.
51. Parenti CM, Lederle FA, Impola CL, Peterson LR. Reduction of unnecessary intravenous catheter use: internal medicine house staff participate in a successful quality improvement project. Arch Intern Med $1994 ; 154: 1829-1832$.

52. Maki DG, Stolz SS, Wheeler S, Mermel LA. A prospective, randomized trial of gauze and two polyurethane dressings for site care of pulmonary artery catheters: implications for catheter management. Crit Care Med 1994; 22:1729-1737.

53. Rasero L, Degl'Innocenti M, Mocali M, et al. Comparison of two different time interval protocols for central venous catheter dressing in bone marrow transplant patients: results of a randomized, multicenter study. Haematologica 2000; 85:275-279.

54. Gillies D, O’Riordan L, Wallen M, Morrison A, Rankin K, Nagy S. Optimal timing for intravenous administration set replacement. Cochrane Database Syst Rev 2005; (4):1-42.

55. Gastmeier P, Geffers C, Brandt C, et al. Effectiveness of a nationwide nosocomial infection surveillance system for reducing nosocomial infections. J Hosp Infect 2006; 64:16-22.

56. National Healthcare Safety Network (NHSN), Department of Health and Human Services, Centers for Disease Control and Prevention. Available at: http://www.cdc.gov/ncidod/dhqp/nhsn.html. Accessed July 15, 2008.

57. Edwards JR, Peterson KD, Andrus ML, et al. National Healthcare Safety Network (NHSN) report, data summary for 2006, issued June 2007. Am J Infect Control 2007; 35:290-301.

58. Levin A, Mason AJ, Jindal KK, Fong IW, Goldstein MB. Prevention of hemodialysis subclavian vein catheter infections by topical povidoneiodine. Kidney Int 1991; 40:934-938.

59. Zakrzewska-Bode A, Muytjens HL, Liem KD, Hoogkamp-Korstanje JA. Mupirocin resistance in coagulase-negative staphylococci, after topical prophylaxis for the reduction of colonization of central venous catheters. J Hosp Infect 1995; 31:189-193.

60. Riu S, Ruiz CG, Martinez-Vea A, Peralta C, Oliver JA. Spontaneous rupture of polyurethane peritoneal catheter: a possible deleterious effect of mupirocin ointment. Nephrol Dial Transplant 1998; 13:1870-1871.

61. Lok CE, Stanley KE, Hux JE, Richardson R, Tobe SW, Conly J. Hemodialysis infection prevention with polysporin ointment. J Am Soc Nephrol 2003; 14:169-179.

62. Fong IW. Prevention of haemodialysis and peritoneal dialysis catheter related infection by topical povidone-iodine. Postgrad Med J 1993; 69(Suppl 3):S15-S17.

63. Bleasdale SC, Trick WE, Gonzales IM, Lyles RD, Hayden MK, Weinstein RA. Effectiveness of chlorhexidine bathing to reduce catheter-associated bloodstream infections in medical intensive care unit patients. Arch Intern Med 2007; 167:2073-2079.

64. Maki DG, Stolz SM, Wheeler S, Mermel LA. Prevention of central venous catheter-related bloodstream infection by use of an antisepticimpregnated catheter: a randomized, controlled trial. Ann Intern Med 1997; 127:257-266.

65. Raad I, Darouiche R, Dupuis J. Central venous catheters coated with minocycline and rifampin for the prevention of catheter-related colonization and bloodstream infections: a randomized, double-blind trial. The Texas Medical Center Catheter Study Group. Ann Intern Med 1997; 127:267-274.

66. Veenstra DL, Saint S, Saha S, Lumley T, Sullivan SD. Efficacy of antiseptic-impregnated central venous catheters in preventing catheter-related bloodstream infections: a meta-analysis. JAMA 1999; 281:261-267.

67. Darouiche RO, Raad II, Heard SO, et al. A comparison of two antimicrobial-impregnated central venous catheters: Catheter Study Group. N Engl J Med 1999; 340:1-8.

68. Hanna HA, Raad II, Hackett B, et al., M.D. Anderson Catheter Study Group. Antibiotic-impregnated catheters associated with significant decrease in nosocomial and multidrug-resistant bacteremias in critically ill patients. Chest 2003; 124:1030-1038.

69. Hanna H, Benjamin R, Chatzinikolaou I, et al. Long-term silicone central venous catheters impregnated with minocycline and rifampin decrease rates of catheter-related bloodstream infection in cancer patients: a prospective randomized clinical trial. J Clin Oncol 2004; 22:3163-3171. 
70. Rupp ME, Lisco SJ, Lipsett PA, et al. Effect of a second-generation venous catheter impregnated with chlorhexidine and silver sulfadiazine on central catheter-related infections: a randomized, controlled trial. Ann Intern Med 2005; 143:570-580.

71. Chelliah A, Heydon KH, Zaoutis TE, et al. Observational trial of antibiotic-coated central venous catheters in critically ill pediatric patients. Pediatr Infect Dis J 2007; 26:816-820.

72. Bhutta A, Gilliam C, Honeycutt M, et al. Reduction of bloodstream infections associated with catheters in paediatric intensive care unit: stepwise approach. BMJ 2007; 334:362-365.

73. Garland JS, Alex CP, Mueller CD, et al. A randomized trial comparing povidone-iodine to a chlorhexidine gluconate-impregnated dressing for prevention of central venous catheter infections in neonates. Pediatrics 2001; 107:1431-1436.

74. Levy I, Katz J, Solter E, et al. Chlorhexidine-impregnated dressing for prevention of colonization of central venous catheters in infants and children: a randomized controlled study. Pediatr Infect Dis J 2005; 24: 676-679.

75. Ho KM, Litton E. Use of chlorhexidine-impregnated dressing to prevent vascular and epidural catheter colonization and infection: a meta-analysis. J Antimicrob Chemother 2006; 58:281-287.

76. Carratala J, Niubo J, Fernandez-Sevilla A, et al. Randomized, doubleblind trial of an antibiotic-lock technique for prevention of gram-positive central venous catheter-related infection in neutropenic patients with cancer. Antimicrob Agents Chemother 1999; 43:2200-2204.

77. Henrickson KJ, Axtell RA, Hoover SM, et al. Prevention of central venous catheter-related infections and thrombotic events in immunocompromised children by the use of vancomycin/ciprofloxacin/heparin flush solution: a randomized, multicenter, double-blind trial. J Clin Oncol 2000; 18:1269-1278.

78. Safdar N, Maki DG. Use of vancomycin-containing lock or flush solutions for prevention of bloodstream infection associated with central venous access devices: a meta-analysis of prospective, randomized trials. Clin Infect Dis 2006; 43:474-484.

79. Labriola L, Crott R, Jadoul M. Preventing haemodialysis catheter-related bacteraemia with an antimicrobial lock solution: a meta-analysis of prospective randomized trials. Nephrol Dial Transplant 2008; 23:16661672.

80. Saxena AK, Panhotra BR, Naguib M. Sudden irreversible sensory-neural hearing loss in a patient with diabetes receiving amikacin as an antibiotic heparin lock. Pharmacotherapy 2002; 22:105-8.

81. McKee R, Dunsmuir R, Whitby M, Garden OJ. Does antibiotic prophylaxis at the time of catheter insertion reduce the incidence of catheter-related sepsis in intravenous nutrition? J Hosp Infect 1985; 6:419425.

82. Ranson MR, Oppenheim BA, Jackson A, Kamthan AG, Scarffe JH. Double-blind placebo controlled study of vancomycin prophylaxis for central venous catheter insertion in cancer patients. J Hosp Infect 1990; 15:95-102.

83. Sandoe JA, Kumar B, Stoddart B, et al. Effect of extended perioperative antibiotic prophylaxis on intravascular catheter colonization and infection in cardiothoracic surgery patients. J Antimicrob Chemother 2003; 52:877-879.

84. Van de Wetering MD, van Woensel JBM, Kremer LCM, Caron HN. Prophylactic antibiotics for preventing early Gram-positive central venous catheter infections in oncology patients, a Cochrane systematic review. Cancer Treat Rev 2005; 31:186-196.

85. Eyer S, Brummitt C, Crossley K, Siegel R, Cerra F. Catheter-related sepsis: prospective, randomized study of three methods of long-term catheter maintenance. Crit Care Med 1990; 18:1073-1079.

86. Cobb DK, High KP, Sawyer RG, et al. A controlled trial of scheduled replacement of central venous and pulmonary-artery catheters. $N$ Engl J Med 1992; 327:1062-1068.

87. Cook D, Randolph A, Kernerman P, et al. Central venous catheter replacement strategies: a systematic review of the literature. Crit Care Med 1997; 25:1417-1424.
88. Maragakis LL, Bradley KL, Song X, et al. Increased catheter-related bloodstream infection rates after the introduction of a new mechanical valve intravenous access port. Infect Control Hosp Epidemiol 2006; 27: 67-70.

89. Field $\mathrm{K}, \mathrm{McF}$ arlane $\mathrm{C}$, Cheng $\mathrm{AC}$, et al. Incidence of catheter-related bloodstream infection among patients with a needleless, mechanical valve-based intravenous connector in an Australian hematology-oncology unit. Infect Control Hosp Epidemiol 2007; 28:610-613.

90. Salgado CD, Chinnes L, Paczesny TH, Cantey JR. Increased rate of catheter-related bloodstream infection associated with use of a needleless mechanical valve device at a long-term acute care hospital. Infect Control Hosp Epidemiol 2007; 28:684-688.

91. Rupp ME, Sholtz LA, Jourdan DR, et al. Outbreak of bloodstream infection temporally associated with the use of an intravascular needleless valve. Clin Infect Dis 2007; 44:1408-1414.

92. Fridkin SK, Pear SM, Williamson TH, Galgiani JN, Jarvis WR. The role of understaffing in central venous catheter-associated bloodstream infections. Infect Control Hosp Epidemiol 1996; 17:150-158.

93. Robert J, Fridkin SK, Blumberg HM, et al. The influence of the composition of the nursing staff on primary bloodstream infection rates in a surgical intensive care unit. Infect Control Hosp Epidemiol 2000; 21: 12-17.

94. Stone PW, Mooney-Kane C, Larson EL, et al. Nurse working conditions and patient safety outcomes. Med Care 2007; 45:571-578.

95. Miller JM, Goetz AM, Squier C, Muder RR. Reduction in nosocomial intravenous device-related bacteremias after institution of an intravenous therapy team. J Intraven Nurs 1996; 19:103-106.

96. Soifer NE, Borzak S, Edlin BR, Weinstein RA. Prevention of peripheral venous catheter complications with an intravenous therapy team: a randomized controlled trial. Arch Intern Med 1998; 158:473-477.

97. Tokars JI, Klevens RM, Edwards JR, Horan TC. Measurement of the impact of risk adjustment for central line-days on interpretation of central line-associated bloodstream infection rates. Infect Control Hosp Epidemiol 2007; 28:1025-1029.

98. Klevens RM, Tokars JI, Edwards J, et al. Sampling for collection of central line-day denominators in surveillance of healthcare-associated bloodstream infections. Infect Control Hosp Epidemiol 2006; 27:338-342.

99. Institute for Healthcare Improvement. Central line insertion checklist. Available at: http://www.ihi.org/IHI/Topics/CriticalCare/IntensiveCare/ Tools/CentralLineInsertionChecklist.htm. Accessed July 30, 2008.

100. Widmer AF, Nettleman M, Flint K, Wenzel RP. The clinical impact of culturing central venous catheters: a prospective study. Arch Intern Med 1992; 152:1299-1302.

101. Raad II, Baba M, Bodey GP. Diagnosis of catheter-related infections: the role of surveillance and targeted quantitative skin cultures. Clin Infect Dis 1995; 20:593-597.

102. Pittet D, Wenzel RP. Nosocomial bloodstream infections: secular trends in rates, mortality, and contribution to total hospital deaths. Arch Intern Med 1995; 155:1177-1184.

103. Wong ES, Rupp ME, Mermel L, et al. Public disclosure of healthcareassociated infections: the role of the Society for Healthcare Epidemiology of America. Infect Control Hosp Epidemiol 2005; 26:210-212.

104. McKibben L, Horan TC, Tokars JI, et al. Guidance on public reporting of healthcare-associated infections: recommendations of the Healthcare Infection Control Practices Advisory Committee. Infect Control Hosp Epidemiol 2005; 26:580-587.

105. Healthcare-Associated Infection Working Group of the Joint Public Policy Committee. Essentials of public reporting of healthcare-associated infections: a tool kit. January 2007. Available at: http://www.cdc .gov/ncidod/dhqp/pdf/ar/06_107498_Essentials_Tool_Kit.pdf. Accessed July 15, 2008.

106. The National Quality Forum. National voluntary consensus standards for the reporting of healthcare-associated infection data: a consensus report. Available at: http://www.qualityforum.org/pdf/reports/HAI \%20Report.pdf. Accessed August 25, 2008. 